\section{Comments Regarding Masroor et al: Perceptions and Barriers to Universal Gloving for Infection Prevention}

To the Editor-Masroor et $\mathrm{al}^{1}$ reported an additional way to investigate the gloving rate: perceptions of healthcare workers (HCWs) and their interaction with the perception of patients. The authors were right to seek responses from every HCW, considering that other studies have shown that gloving is determined by the behavior of all HCWs. ${ }^{2}$ The results reported by Masroor et al showed that HCWs were ambivalent: On the one hand, they knew that gloving reduces cross transmission risk; on the other hand, they considered gloving an inconvenience. These results are consistent with the results of a study we conducted among our hospital nursing aides. However, our study revealed 2 other barriers to the adoption of gloving.

We studied compliance with the use of personal protective equipment (PPE) among 121 nursing aides (NA) when they had self-reported exposure to biological hazards and to chemical hazards. ${ }^{3}$ Indeed, nursing aides can also be exposed to chemical contamination risk, in particular when they handle antineoplastic drugs. ${ }^{4}$ We used 2 criteria to assess the PPE compliance rate: (1) the use of gloves when there was a risk and (2) the appropriate use of gloves to counter the risk. We analyzed their work and administered a self-reported questionnaire regarding their knowledge of hospital PPE rules.

For biological hazards, compliance rates in our sample were between $67 \%$ and $77 \%$. However, the nursing aides in pediatric units were not as compliant, in particular, in caring for babies. The compliance rates were only $30 \%$ when nursing aides in pediatric units were exposed to infantile disease. The non-compliant nursing aides used alcohol-based hand products between patients, so there was no risk of crosstransmission of infection to the patients. Most nursing aides explained their actions by claiming potential harm to the patient-provider relationship if gloves were used.

For chemical hazards, the compliance rates were between $75 \%$ and $100 \%$. When we asked why some nursing aides did not use PPE to counter chemical risk, their answers revealed another barrier to PPE use. Some nursing aides thought that vinyl gloves were reserved for non-HCWs and/or projected a social image of janitorial staff. Additionally, nursing aides thought that only latex gloves projected the image of healthcare professionals. This belief prevented them from following PPE rules.

These results compliment the study by Masroor et al. ${ }^{1}$ It is important to consider the perceptions of HCWs to promote gloving. Sociological representations can influence the behavior of HCWs. Furthermore, compliance is usually higher for some kinds of care (eg, surgical procedures, etc). ${ }^{5}$ Certainly, it would be easy to assume that universal gloving prevents these sociologic phenomena. ${ }^{6}$ Indeed, the population will gradually accept gloving, but these social barriers may remain a limiting factor as this change is more universally implemented in the coming years because it often takes a long time to change mindsets and behaviors.

\section{ACKNOWLEDGMENTS}

Financial support. No financial support was provided relevant to this article.

Potential conflicts of interest. All authors report no conflicts of interest relevant to this article.

\section{Richard Pougnet, $\mathrm{MD} ;{ }^{1,2}$ Laurence Pougnet, $\mathrm{MD}{ }^{3}$ Ronan Garlantézec, $\mathrm{MD}, \mathrm{PhD}^{4}$}

Affiliations: 1. Teaching Hospital, Environmental Diseases Center, Brest, France; 2. EA 4686, Medical Ethics (Ethique, Professionnalisme et Santé), European University of Britany, Brest, France; 3. Infection Control Team, Military Hospital Clermont-Tonnerre, Brest, France; 4. Public Health, European Universitary of Brittany, Rennes, France.

Address correspondence to Richard Pougnet, MD, 10 rue des onze martyrs, 29200 Brest France (richard.pougnet@live.fr).

Infect. Control Hosp. Epidemiol. 2016;37(4):488-488

(C) 2016 by The Society for Healthcare Epidemiology of America. All rights reserved. 0899-823X/2016/3704-0021. DOI: 10.1017/ice.2016.6

\section{REFERENCES}

1. Masroor N, Donovan SD, Sanogo K, Couture L, Ober J, Stevens MP, Bearman G. Perceptions and barriers to universal gloving for infection prevention: a survey of healthcare workers and patients. Infect Control Hosp Epidemiol 2015;4:1-2.

2. Turco M, Chalaye C, Poulard E, Gocko C, Neyron C, Courbon G, Berthelot P. Evaluating the impact of pluridisciplinary training on proper glove use in hospital. Med Mal Infect 2014;44:268-274.

3. Pougnet R, Garlantézec R, Sawicki B, Loddé B, Eniaffe-Eveillard BM, Le Menn A, Dewitte JD. Expositions aux produits biologiques et chimiques des aides-soignants d'un CHRU: fréquence d'exposition et conformité du port des équipements de protection. Arch Mal Pro 2012;73:9-19.

4. Boiano JM, Steege AL, Sweeney MH. Adherence to safe handling guidelines by health care workers who administer antineoplastic drugs. J Occup Environ Hyg 2014;11:728-740.

5. Goudra B, Singh PM, Galvin E. Comparison of compliance of glove use among anesthesia providers: a prospective blinded observational study. AANA J 2014;82:363-367.

6. Yin J, Schweizer ML, Herwaldt LA, Pottinger JM, Perencevich EN. Benefits of universal gloving on hospital-acquired infections in acute care pediatric units. Pediatrics 2013;131: e1515-e1520. 